\title{
4
}

\section{Conserved Regulatory Mechanisms Controlling Aflatoxin and Sterigmatocystin Biosynthesis}

\author{
Ana M. Calvo and Sourabh Dhingra \\ Northern Illinois University, \\ USA
}

\section{Introduction}

Filamentous fungi produce a wide array of compounds known as secondary metabolites or natural products (i.e. Adrio and Demain, 2003; Reverberi et al 2010; Brakhage and Schroeckh 2011). The exact function of these compounds is unknown but it is postulated that they provide fungi with an advantage in their ecological niche (Keller et al., 2005; Georgianna and Payne 2009). The broad group of natural products includes compounds such as antibiotics, pigments and also mycotoxins (Fig.1). Among mycotoxins, aflatoxins (AF), specifically AF B1, are the most potent carcinogenic natural compounds known, and they are mainly produced by the opportunistic plant pathogens Aspergillus flavus and Aspergillus parasiticus (Squire 1989; Sweeny and Dobson 1999; Payne and Brown, 1998). Other AFproducers among Aspergilli include Aspergillus nomius, Aspergillus ochraceoroseus, Aspergillus bombycis and Aspergillus pseudotamari (Cary and Ehrlich, 2006). Aspergillus flavus and Aspergillus parasiticus have the ability to colonize oil seed crops of agricultural importance, such as corn, cotton, peanuts, sorghum and tree nuts. Ingestion of aflatoxin contaminated food can cause hepatocellular carcinoma, immunotoxicity, and teratogenic effects (Dvorackova and Kusak, 1990; Trail et al., 1995; Wogan et al., 1992). Various developed countries have strict regulation on the amount of AF allowed in food commodities. Contaminated crops above the permitted limit have to be destroyed, resulting in economic losses. The annual estimated loss due to AF contamination is attributed at approximately $\$ 270$ million in the USA alone (Richard and Payne, 2003).

It is known that AF and a related mycotoxin called sterigmatocystin (ST) (Fig.2) are synthesized through the same conserved biosynthetic pathway, in which ST is the penultimate precursor. ST is produced by several Aspergillus species, including Aspergillus nidulans, one of the most characterized eukaryotic systems that has been used as a model organism for more than 60 years (Pontecorvo et al., 1953). The elevated number of characterized $A$. nidulans genes and mutant strains makes this model fungus ideal for genetic and molecular studies. There is a physical and genetic map of the eight chromosomes in A. nidulans. The whole A. nidulans genome has been sequenced and annotated, and has been compared with other Aspergillus genomes (David et al., 2008; Galagan et al., 2005). Structural and signaling pathway genes controlling ST production in A. nidulans are also found in AF-producer Aspergillus spp. (Hicks et al., 1997; reviewed by 
Calvo et al., 2002; Calvo, 2008). For these reasons this model system is especially productive in the study of the AF/ST gene clusters and regulatory pathways directing mycotoxin production. In this review we will focus on these common regulatory mechanisms governing AF and ST biosynthesis in A. flavus and A. parasiticus, and in A. nidulans.

\section{AF/ST gene clusters}

ST/AF gene clusters remain some of the best characterized mycotoxin gene clusters. Both encode enzymes participating in 29 metabolic steps along with two regulatory proteins, AflR and AflS. (Cary et al., 2009). Both gene clusters extend to approximately $70 \mathrm{~kb}$ in the genome (Brown et al., 1996; Cary and Ehrlich, 2006; Ehrlich et al., 2005; Cary et al., 2009). The order and direction of genes in AF and ST clusters is conserved for all genes except four in AF pathway and three in ST which are inverted. It has been hypothesized that these differences might have been the result of gene reorganization from an ST-producing ancestor by recombination and duplications of near-telomeric regions where these clusters are found (Cary et al., 2009; Carbone et al., 2007). Based on phylogenetic analysis, the clusters may be 450 million years old (Galagan et al., 2005).

The enzymatic reactions and chemistry involved in the AF/ST biosynthetic pathway have already been extensively covered in previous reviews (Bhatnagar et al., 2003; Bennett and Klich, 2003; Hicks et al., 2002; Huffman et al., 2010; Keller et al., 2005; Minto and Townsend, 1997; Payne and Brown, 1998; Yabe and Nakajima, 2004), and will not be addressed in this review. Beyond the genus Aspergillus, other fungi present semi-conserved pathways, for example Dothistroma septosporum, which produces a metabolite that resembles versicolorin $\mathrm{B}$, a precursor of both ST and AF. This suggests further cluster conservation across fungal genera (Bradshaw and Zhang, 2006).

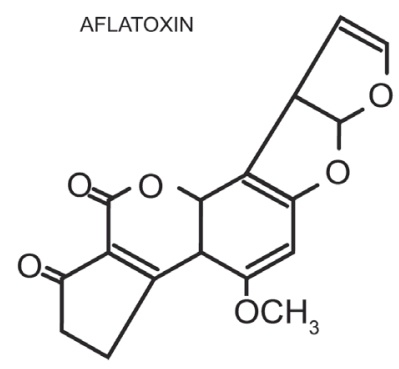<smiles>CCONOc1cc2c(c3oc4cccc(O)c4c(=O)c13)C1C=COC1O2</smiles>

Fig. 1. Chemical structures of the mycotoxins aflatoxin and sterigmatocystin. 


\section{AfIR and AfIS}

In addition to the structural genes, two regulatory genes are also included in these clusters, aflR and aflS (formerly known as aflJ). The gene products AflR and AflS, are specific regulators for AF/ST gene cluster activation and for concomitant AF/ST production. AflR, encodes a transcription factor with a cysteine rich Gal4 type bi-nuclear zinc finger cluster (Chang et al., 1995; Yu et al., 1996). AflR has been shown to control most of the steps of the ST/AF biosynthetic pathway. AflR binds DNA at the consensus motif 5'TCGN5CGA3' in the promoter of biosynthetic genes (Fernandes et al., 1998). More than one AflR binding site is common in promoters of AF genes (Cary et al., 2009; Cary et al., 2000). Despite the differences between A. nidulans and A. flavus AflR, the function is conserved (Yu et al., 1996). Deletion aflR ( $\triangle a f l R)$ strain in A. flavus and A. nidulans fails to produce AF and ST respectively. Additionally, heterologously expressed A. flavus aflR in the deletion $A$. nidulans $\triangle a f l R$ strain is able to activate the ST gene cluster, supporting functional conservation (Yu et al., 1996). In A. parasiticus, a microarray comparison of $\triangle a f l R$ and wild-type strains revealed eighteen genes involved in AF pathway to be differentially expressed (Price et al., 2006). Constitutive expression of aflR was shown to increase the transcript of AF cluster genes along with 50 -fold greater aflatoxin production (Flaherty and Payne 1997).

In addition to AflR, AflS also plays a role in the regulation of AF biosynthesis (Meyers et al., 1998; Chang et al., 1993; 2002; Chang, 2003). aflS lies next to aflR in the AF cluster. The gene products AflR and AflS were found to interact in A. parasiticus (Chang, 2003). Deletion of aflS has been shown to decrease expression of several biosynthetic genes in the cluster (Meyers et al., 1998), but does not alter aflR expression (Chang, 2003). The $\Delta$ aflS mutant still produces reduced but detectable levels of AF in A. parasiticus (Meyers et al., 1998). Interestingly, overexpression of aflS, particularly in combination with overexpression of aflR synergically increased expression of biosynthetic genes and AF production (Chang, 2003). Aspergillus sojae, is unable to produce $\mathrm{AF}$ in spite possessing the $\mathrm{AF}$ gene cluster in its genome; its aflR gene has a mutation that results in a truncated protein, which fails to interact with AflS (Chang, 2004).

Our genomic sequence analysis indicates that aflS is also present in A. nidulans, and that it is located next to aflR in the ST gene cluster (Calvo et al., unpublished data). As in the case of aflS in the AF cluster, A. nidulans aflS transcriptional direction is opposite with respect to that of aflR, sharing an intergenic region of $599 \mathrm{bp}$.

\section{Global regulation}

\subsection{VeA and VeA-interacting proteins}

Global regulatory mechanisms that control different cell functions, including morphogenesis and secondary metabolism tend to be conserved across fungal species. The velvet gene or veA is an example of global regulation. VeA is unique to fungi and is highly conserved in Ascomycetes (Myung et al., 2011). This regulator controls the morphological balance between sexual and asexual development (Kim et al., 2002; Li et al., 2006; Calvo, 2008). Interestingly, our laboratory showed for the first time that VeA also controls the production of numerous secondary metabolites, including ST and AF production in A. nidulans, and A. flavus and A. parasiticus (Kato et al., 2003; Calvo et al., 2004; Duran et al., 2007; Carry et al., 2007). In A. nidulans and later in A. flavus it has been demonstrated that 
$v e A$ is necessary for aflR transcription, and therefore controls the expression of the ST/AF clustered genes (Kato et al., 2003; Duran et al., 2007).

The effect of VeA on secondary metabolism is broad. In A. nidulans the production of other metabolites, including penicillin, is also affected by the absence of $v e A$ (Kato et al., 2003). In A. flavus, the biosynthesis of other mycotoxins is also veA-dependent, such as the case of cyclopiazonic acid and aflatrem, where we showed that expression of aflatrem genes requires a veA wild-type allele (Duran et al., 2007).

VeA is also conserved across fungal genera, for example the veA homolog FvVE1 in Fusarium verticilliodies (Li et al., 2006; Myung et al., 2009), AcveA in Acremonium chrysogenum (Dreyer et al., 2007) and ve-1 in Neurospora crassa (Bayram et al., 2008). Studies in these organisms also link veA to secondary metabolism. The veA regulatory system has been extensively reviewed (Calvo, 2008). VeA is transported to the nucleus (Stinnett et al., 2007) where it forms interactions with other regulatory proteins that also influence morphogenesis, and secondary metabolism, including production of mycotoxin (Purschwitz et al., 2008; Calvo, 2008; Bayram et al., 2008; Bayram et al., 2010).

In $A$. nidulans it has been shown that VeA interacts with a protein called LaeA (Bayram et al., 2008). laeA is also necessary for ST/AF production. Unlike veA, which has been shown to control $A$. nidulans asexual/sexual morphological development, laeA has a mild effect on morphogenesis, influencing Hülle cell numbers (Bayram et al., 2010). However, in A. flavus both veA and laeA have an important role in morphogenesis, being necessary for sclerotial production (Duran et al., 2007; Duran et al., 2009; Kale et al., 2008). LaeA is a putative methyl transferase, with an S-adenosylmethionine binding domain (Bok and Keller, 2004). In $A$. flavus it has been shown that laeA is a negative regulator of $v e A$ transcription (Kale et al., 2008). In addition, increased expression of veA (in a strain with multiple veA copies) results in decreased laeA expression (Amaike and Keller, 2009), suggesting a mutual negative transcriptional regulatory feedback control.

In addition to transcriptional regulation between $v e A$ and lae $A$, recent studies also suggest posttranslational regulation (Bayram et al., 2010); a new form of the VeA protein with higher molecular weight has been detected in $\triangle l a e A$ strains, indicating that in the wild type, laeA prevents a modification of the VeA protein (Bayram et al., 2010).

Another protein from the velvet family, VelB, has been shown to interact with VeA. The $\Delta v e l B$ strain produces a reduced and delayed but still detectable amount of ST. VelB protein also interacts with VosA, a positive regulator of sporogenesis ( $\mathrm{Ni}$ and $\mathrm{Yu}$ 2007; Bayram et al., 2010). Homologs of velB and vosA are present in A. flavus genome (data not shown). Other VeA-interacting proteins, such as the light-response mediating proteins FphA, LreA and LreB (Purschwitz et al., 2008), also influence morphological and metabolic changes in response to environmental stimuli affecting mycotoxin production (see section below corresponding to the effect of light).

\section{2 $\mathrm{G}$ protein signalling}

Several cellular functions, including fungal growth, morphogenesis and secondary metabolism are governed by G-protein signalling pathways. For example, the A. nidulans $\mathrm{fad} A$ gene encodes an a subunit of an heterotrimeric $\mathrm{G}$ protein complex where FadA

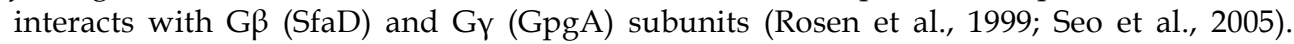
Mutations in FadA blocking the intrinsic GTPase activity results in a permanently active stage of this protein (Hicks et at., 1997). It is likely that activation of FadA upregulates 
adenylyl cyclase and cAMP-dependent kinase PKA. Activation of FadA or overexpression of PKA results in an increase in vegetative growth and reduction of asexual development, as well as reduction in ST production (Hicks et al., 1997; Shimizu and Keller, 2000). It has been shown that overexpression of PKA represses aflR expression (Shimizu and Keller, 2000). In addition to transcriptional regulation of ST genes, PKA also regulates ST production at posttranslational level. PKA negatively regulates the localization of AflR protein in the nucleus by phosphorylation (Shimizu et al., 2003). In A. parasiticus PKA also negatively regulates AF production (Roze et al., 2004). Additionally, expression of the FadA constitutive active form also resulted in a decrease of AF intermediates and a reduction in conidiation in A. parasiticus (Hicks et al., 1997). These findings strongly indicate a conservation of the FadA-PKA signaling pathway in regulating ST and AF production.

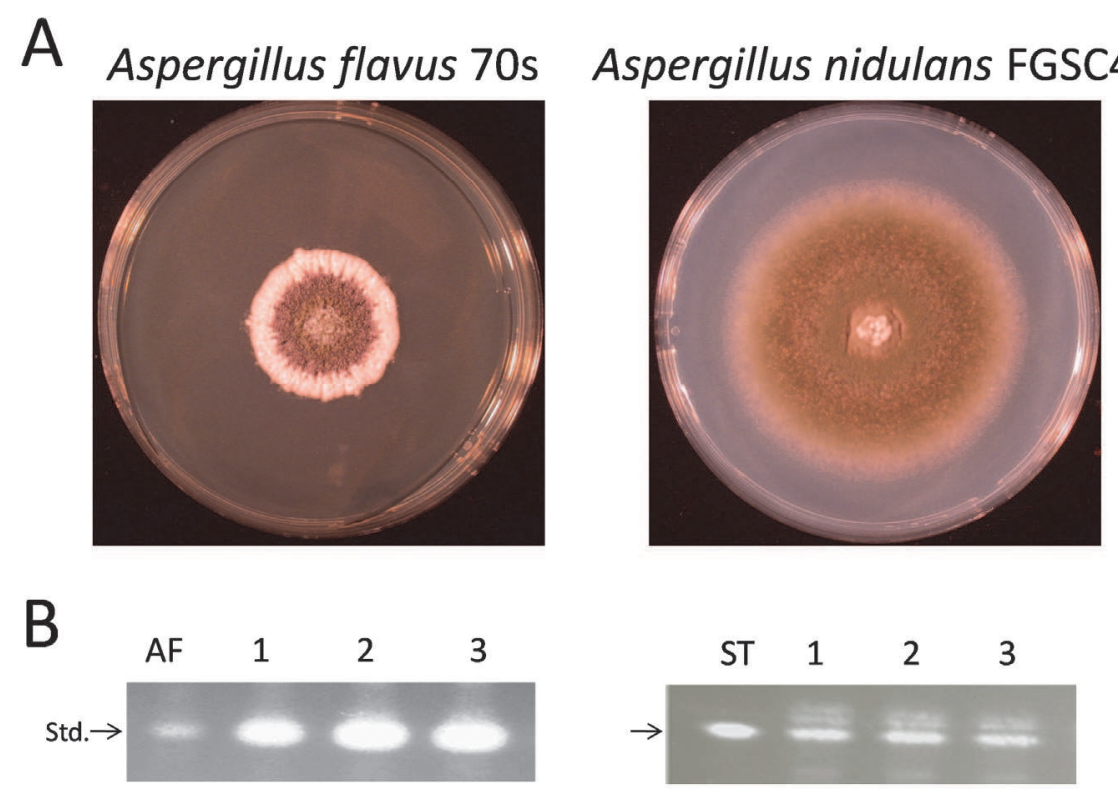

Fig. 2. Aspergillus flavus (70S) and Aspergillus nidulans (FGSC 4) wild type strains.

A) Point-inoculated cultures incubated for five days. B) Thin layer chromatography analysis of the mycotoxins aflatoxin and sterigmatocystin. The chemical analysis was carried out as previously described (Kato et al., 2003; Duran et al., 2007). Std. = Standard, $\mathrm{AF}=$ Aflatoxin, $\mathrm{ST}=$ Sterigmatocystin. $1-3$ represent replicates.

In the wild type, FadA is regulated by FluG, which activates transcription of $f l b A$, encoding a GTPase activating protein that negatively regulates FadA (Lee and Adams, 1994; 1996; Seo et al., 2003. Both, $f l u G$ and $f l b A$ are necessary for ST production (Calvo et al., 2002). Homologs are also present in the A. flavus genome (data not shown).

Further studies showed of role of the FadA-interacting proteins, SfaD and GpgA subunits, and PhnA, a positive regulator of $G \beta Y$, as positive regulators of aflR and consequently ST biosynthesis (Seo and Yu, 2006). 


\subsection{MpkB signalling}

In eukaryotes Mitogen Activated Protein (MAP) kinases play a crucial role in signal transduction to the nucleus to control differentiation and cell growth (Banuett, 1998; Bradwell, 2006; Brown et al., 1996). For instance, in Saccharomyces cerevisiae, the MAP kinase FUS3 is known to regulate mating (Doi et al., 1994; Zhan et al., 1997). In A. nidulans and other filamentous fungi, homologs of FUS3 have been characterized (i.e. Atoui et al., 2008; Chen et al., 2004; Cousin et al., 2006; Di Petro et al., 2001; Jenczmionka et al., 2003; Li D. et al., 2005; Mey et al., 2002; Moriwaki et al., 2007; Rauyaree et al., 2005; Ruiz-Roldman et al., 2001; Takano et al., 2000; Xu et al., 1996;). Our laboratory has shown that the A. nidulans FUS3 homolog, $m p k B$, controls sexual development and secondary metabolism (Paoleti et al., 2007; Atoui et al., 2008). $m p k B$ affects expression of laeA, a global regulator of secondary metabolism (See Section Global Regulation). The $A$. nidulans $\triangle m p k B$ strain presents decreased transcript levels of aflR and of ST structural genes, consequently the $\Delta m p k B$ mutant failed to produce ST. Production of other secondary metabolites such as the antibiotic penicillin and the anti-tumoral compound terrequinone A was also affected (Atoui et al., 2008). Since FUS3 homologs are also present in other fungal species, its role may be conserved in the AF-producing fungi.

\subsection{Metabolic channeling}

Chanda et al. (2009) also showed the importance of aflatoxigenic vesicles called aflatoxisomes in aflatoxin biosynthesis, storage and transport in A. parasiticus. High vesicle numbers were directly linked to AF-inducing growth conditions and inversely linked to lower expression of $v b 1$ (homolog of AvaA in A. nidulans) and vps16 (another protein of Class C Vps tethering complex blocked by Sortin3). The wild type strain of A. parasiticus showed decreased transcript levels of $v b 1$ and vps16, whereas transcripts levels were constant in the $\Delta v e A$ strain. This suggests a direct role for VeA in aflatoxisome production by down-regulating $v b 1$ and vps16.

\subsection{Chromosome remodeling}

Secondary metabolism gene clusters are often located in the chromosomal near-telomeric regions (Nierman et al., 2005; Rehmeyer et al., 2006), associated with epigenetic regulation. In 2004, Roze et al. identified CRE1 protein binding sites involved in the cAMP response. CRE1 protein recruits a histone acetyl transferase to the promoters of AF genes, resulting in acetylation of histones, specifically H4, favoring transcriptional activation (Shahbazian and Grunstein, 2007; Spencer and Davie, 1999; Daniel et al., 1998). Roze et al., (2007) showed the effect of histone H4 acetylation on transcript level of "early", "middle" and "late" genes of the AF cluster that leads to aflatoxin in A. parasiticus. The proposed model involves the activation of cAMP/PKA pathway by a decrease of glucose sensed by G-protein couple receptors. Activation of PKA would lead to CRE1 protein binding and recruiting of the histone acetyl transferase. This is followed by histone acetylation and AF gene expression, enhanced by AflR binding to the accessible promoter regions.

The effect of histone acetylation on mycotoxin production was further supported by $A$. nidulans studies, where deletion of the histone deacetylase gene, $h d a A$, lead to an increase in ST production by activation of transcription of ST genes. Deletion of $h d h A$ also increased the production of other secondary metabolites such as penicillin (Shwab et al., 2007). 


\section{Environmental factors}

\subsection{Light}

The effect of light on production of AF in A. flavus and A. parasiticus has been previously described (Joffe and Lisker, 1969; Bennett and Dunn et al., 1981). In these studies lightmediated regulation of mycotoxin production was conditioned by the incubation temperature. Light regulates morphological development as well as ST production in A. nidulans. A strain with a $v e A$ wild-type allele $(v e A+)$ develops asexually forming conidiophores in the light, while in the dark this fungus preferentially forms fruiting bodies called cleistothecia. A. nidulans produces more ST in the dark than in the light when cultured on glucose minimum medium. In the dark VeA is efficiently transported to the nucleus by the importin- $\alpha$ KapA (Stinnett et al., 2007), leading to ST biosynthesis. Interestingly, $A$. nidulans veA1 mutants, with a truncated VeA protein missing the first 36 amino acids, produce less toxin compared to the veA+ strains (Stinnett et al., 2007). The truncation at the VeA N-terminal in veA1 strains results in alterations of the binding with KapA and VeA transport (Stinnett et al., 2007; Araujo-Bazan et al., 2009).

Differential VeA localization was observed using blue and red light. Blue light had a similar effect to that with white light, decreasing VeA transport to nucleus, however, efficient nuclear localization was observed under red light, a result similar to that in dark conditions (Stinnett et al., 2007). This coincides with greater ST production under red light as compared to blue light. A red phytochrome-like protein, FphA, interacts directly with VeA in the nucleus (Purschwitz et al., 2008). Also, LreA and LreB, orthologs of the N. crassa blue collar protein CW1 and CW2 respectively, interact with VeA indirectly via FphA. Under light FphA negatively regulates VeA nuclear transport (Purschwitz et al., 2008). FphA and LreA/B proteins have opposite effects regulating secondary metabolism. $\Delta f p h A$ strain of $A$. nidulans produced more ST than the wild type, whereas a reduction of toxin is observed in the $\Delta$ lre $A$ and $\Delta$ lreB mutants. Homologs of fphA, lreB and lreA are present in the A. flavus genome, suggesting that the corresponding gene products could also be involved in AF regulation (data not shown).

\subsection{Carbon source}

It has been shown that AF is produced from glucose derived acetyl-CoA (Buchanan and Lewis, 1984, Shantha and Murthy, 1981). Simple sugar like glucose, sucrose, fructose or sorbitol enhances AF production, while complex carbon sources like peptone, galactose, xylulose, mannitol and lactose are not conducive to AF biosynthesis (Calvo et al., 2002 and references therein). A microarray analysis conducted on A. parasiticus showed that AF genes were differentially expressed when comparing expression levels in YE (medium with low sugar) and YES (medium with sucrose) (Wilkinson et al., 2007). A 10-fold increase in AF was observed within 48 hours in YES medium.

Interestingly, in a recent $A$. nidulans study we showed that the concentration of glucose is predominant to the effect of light on ST production (Atoui et al., 2010). Higher levels of ST were produced in the dark at low glucose concentration $(1 \%)$ with respect to those produced in light cultures, however, more ST was observed in cultures exposed to light when higher amounts of glucose were added (i.e. $2 \%$ ). These results also correlate with differential aflR expression levels in each case (Atoui et al., 2010). These findings indicate that the response to different environmental factors, such as light and carbon source on secondary metabolism occur integratively leading to an adaptation to a complex environment. 


\subsection{Nitrogen source}

Nitrogen metabolism affects mycotoxin production. However the effect of nitrogen varies depending on the nitrogen source utilized. Whereas organic nitrogen sources induce AF production, nitrate as the sole nitrogen source in the medium is non-conducive to AF production (Georgianna and Payne, 2009). This differs from ST production in A. nidulans, where ST levels increase in medium with nitrate and are reduced when ammonia is used (Feng and Leonard, 1998).

In A. parasiticus, Chang et al.(2000) reported a major nitrogen utilization regulatory factor called AreA. This protein has been previously well characterized in A. nidulans where it has been shown to be a member of the GATA family of transcription factors and mediates nitrogen metabolite repression (Wilson and Arst, 1998). Overexpression of aflR in A. parasiticus overcomes the nitrate inhibition of AF production suggesting that AreA regulatory effect on mycotoxin biosynthesis could be linked to aflR regulation (Chang et al., 1995). Later it was demonstrated that AreA is able to bind to the intergenic region between aflR and aflJ, where several GATA binding sites are located (Chang et al., 2000).

Analysis of the effect of nitrate on AF biosynthesis and aflR and alfS expression in different A. flavus strains showed variability. This could be due variation in the number of AreA binding sites present in the intergenic region between aflR-aflJ (Ehrlich and Cotty, 2002). In addition, Marzluf (1997) suggests that nitrate utilization requiring induction and expression of several enzymes for reduction of nitrate to ammonium, could cause a delay in nitrogen utilization for AF biosynthesis. This may also be viewed as inhibition of biosynthesis (Ehrlich and Cotty, 2002).

\subsection{Temperature}

The effect of temperature on ST and AF biosynthesis is not conserved. While AF is produced between $25-30^{\circ} \mathrm{C}$, ST is produced at a higher temperature, $37^{\circ} \mathrm{C}$. Surprisingly, SchmidtHeydt et al. (2009) showed that aflS (aflJ) expression levels were high at $37^{\circ} \mathrm{C}$, however only low amounts of AF were detected. In addition, a microarray analysis performed by OBrian et al. (2007), showed 144 genes to be differentially expressed when A. flavus was grown at $28^{\circ} \mathrm{C}$ compared to cultures at $37^{\circ} \mathrm{C}$. Out of these, 103 genes were upregulated at $28^{\circ} \mathrm{C}, 25 \%$ of which are involved in secondary metabolism. In this case, not only aflJ(aflS) but also aflR expression levels were similar at both $28^{\circ} \mathrm{C}$ and $37^{\circ} \mathrm{C}$.

A SILAC study by Georgianna et al. (2008) on A. flavus revealed differences in protein levels at $28^{\circ} \mathrm{C}$ and at $37^{\circ} \mathrm{C}$, while RNA transcripts did not change. This could be attributed to posttranslational regulation, where enzymes might not be present or as functional at the higher temperatures. This could also be attributed to the fact that in this study the authors only analyzed the cytosolic proteins, therefore concentration levels might vary due to different subcellular location or possible membrane interactions. Liu and Chu (1998) reported differences in AflR protein levels at $29^{\circ} \mathrm{C}$ when compared to those at $37^{\circ} \mathrm{C}$ using anti-AflR in A. parasiticus. AflR levels were 4 times lower at $37^{\circ} \mathrm{C}$ when compared to protein levels at $28^{\circ} \mathrm{C}$. The difference in temperature-dependent AF production is most likely not related to phosphorylation of AfIR by PKA, since the AflR subcellular localization does not change at $28^{\circ} \mathrm{C}$ or $37^{\circ} \mathrm{C}$ (Georgiana and Payne, 2009).

\section{$5.5 \mathrm{pH}$}

It has been reported that Aspergillus species produce more AF/ST at acidic $\mathrm{pH}$ as compared to alkaline $\mathrm{pH}$ (Keller et al., 1997), which in A. nidulans correlates with an increase in stcU 
expression in acidic environment. This may be attributed in part to the role of alkaline transcription factor $\mathrm{PacC}$, a zinc finger transcription factor that binds to the consensus sequence 5'-GCCAAG-3' (Tilburn et al., 1995). Under acidic condition PacC is in its inactive form whereas under alkaline conditions, $\mathrm{PacC}$ is proteolytically cleaved to gain its active form. In its active form PacC activates expression of alkali expressed genes and represses acidic expressed genes by binding to the consensus sequence in the promoter region (Tilburn et al., 1995). PacC binding sites have been reported in the promoter of aflR, and putative binding sites have also been found on various genes in the cluster of ST/AF (Ehrlich et al., 1999; Keller et al., 1997). Putative binding sites have also been found in the promoter region of veA in different Aspergilli (Calvo et al., unpublished data), which, as mentioned above, is necessary for ST/AF production (Kato et al., 2003; Calvo et al., 2004; Duran et al., 2007).

Interestingly, $\mathrm{PacC}$ has antagonistic roles in controlling penicillin and mycotoxin production (Espeso et al., 1993). PacC-dependent penicillin production and expression of ipnA, gene encoding the isopenicillin $\mathrm{N}$ synthetase, increased under alkaline conditions when compared to acidic conditions.

In contrast with the reports mentioned above, a recent study by Delgado-Virgen and Guzman-de-Pena (2009) showed increased ST production in alkaline $\mathrm{pH}$ with respect to the levels produced at acidic $\mathrm{pH}$. According to this report, aflR transcript levels are elevated in the "alkalinity mimicking" pacCc14 mutant. This opposite effect with respect to previous reports could be due to differences in culture conditions utilized in these two studies (for example Keller et al. used complete minimal medium while Delgado-Virgen and Guzmande-Pena used Käfer minimal medium).

\subsection{Plant metabolites}

Fungal morphogenesis and secondary metabolism can be affected by plant-based compounds (Holmes et al., 2008). For example, volatile aldehydes, jasmonic acid and methyl jasmonate from the plant lipoxygenase pathway have been shown to reduce AF production (i.e. Zeringue and McCormick, 1990, Wright et al., 2000; Norton, 1999; Bhatnagar and MaCormick, 1988; Goodrich-Tanrikulu et al., 1995). Precursors of the lipoxygenase pathway called oxylipins, a family of oxidized polyenoic fatty acids, are found in different kingdoms, including plantae, fungi and monera (Tsitsgiannis and Keller, 2006). They might contribute to a communication established across kingdoms (Tsitsgiannis et al., 2004). In A. nidulans, oxylipin signal molecules called psi factors (Champe et al., 1987), are similar to 13Shydroperoxy linoleic acid and 9S-hydroperoxy linolenic acid commonly found in plants (Calvo et al., 1999; Calvo et al., 2001; Tsitsigiannis et al., 2004). Both 9S-hydroperoxy linoleic acid and 13-hydroperoxy linolenic acid have been shown to differentially affect mycotoxin production; while the former has a stimulatory effect, the latter repressed its synthesis (Burow et al., 1997). Also, these fatty acids affect the balance between sclerotia/cleistothecial formation and conidiation in A. flavus, A. parasiticus and A. nidulans (Calvo et al., 1999). It is possible that these compounds of plant origin could mimic or interfere with the fungal psi factor regulatory mechanism. In $A$. nidulans, several oxylipin genes, $p p o A, p p o B$ and $p p o C$, are responsible for synthesis of linoleic- and linolenic-derived psi factors. ST analysis of oxylipin deletion strains reveal that $\triangle p p o B$ and $\triangle p p o C$ strains produced more toxin than the control strain. On the other hand, $\triangle p p o A$ strain produced less toxin than the wild type. $\triangle p p o A$, $\triangle p p o C$ and $\triangle p p o A, \triangle p p o B, \triangle p p o C$ double and triple mutants trains did not produce any detectable ST (Tsitsgiannis and Keller, 2006). The findings described indicate a direct correlation between presence of oxylipins and mycotoxin production. 
Other compounds such as ethylene and $\mathrm{CO}_{2}$ have been described to reduce AF production (Cary et al., 2009, and reference herein), while other molecules such as 2-ethyl-1-hexanol stimulate mycotoxin biosynthesis or affect it in a dose-dependent manner, such as the case of 2-buten-1-ol (Roze et al., 2007). Interestingly, ethylene, 2-ethyl-1-hexanol and 2-ethyl-1hexanol have also been found to be produced by Aspergillus species, such as A. parasiticus and $A$. nidulans, where they could play a role as signal molecules (Roze et al., 2004; Roze et al., 2007).

\subsection{Nitric oxide}

Other gaseous molecules have been described as signaling molecules in higher eukaryotes. Plamer et al. (1987) and Ignarro et al. (1987) showed that the endothelium-dependent relaxing factor (EDRF) was indeed nitric oxide (NO), produced from L-Arginine (Palmer et al., 1988). Hausladen and Gow et al. (1998) identified a flabohemoglobin 'denitrosolase' in E. coli able to metabolize NO to nitrate. Thus flabohemoglobins were showed to decrease nitrosative stress by detoxifying NO. At low levels, NO is an important signaling molecule controlling numerous cell functions in higher eukaryotes (Wendehenne et al., 2001, Romanov et al., 2008; Roselli et al., 1998; Masuda et al., 2001; Kim et al., 2007; Lamattina et al., 2003). However, until recently there were no studies of $\mathrm{NO}$ as a signaling molecule in fungi. In A. nidulans two flabohemoglobins, FhbA and FhbB, have been reported (Schinko et al., 2010). A recent study in our laboratory (Baidya et al., 2011) showed a link between NO and morphological development and ST production in A. nidulans. This was the first report of the effect of NO in morphogenesis and secondary metabolism in the fungal kingdom (Baidya et al., 2011). Deletion of $f h b A$ results in an increase of sexual development and decrease of ST biosynthesis (Baidya et al., 2011). The reduction of ST was linked to a decrease of aflR expression. Homologs of $f h b A$ and $f h b B$ are present in the A. flavus genome (unpublished data). The implications of this study suggest a broader possible regulatory effect of NO that might also impact AF production as well as the production of other fungal metabolites.

\section{Conclusion}

$\mathrm{AF}$, commonly produced by A. flavus and A. parasiticus, is a potent mutagenic and carcinogenic natural compound that constitutes a health threat worldwide. To set the basis for the development of efficient control strategies to prevent or reduce the negative impact associated with AF contamination it is essential to uncover the regulatory networks that lead to mycotoxin biosynthesis in these fungi. In this review we have shown that studies in the model filamentous fungus $A$. nidulans have facilitated rapid progress in this field, revealing genetic mechanisms governing the production of the mycotoxin ST that are also found conserved in the regulation and production of AF by A. flavus or A. parasiticus. This, combined with the availability of new technologies leading to the genome sequencing of A. nidulans, A. flavus and other filamentous fungi, has further expanded our knowledge on $\mathrm{AF} / \mathrm{ST}$ regulation and biosynthesis.

The elucidation of the genetic mechanisms that operate in response to different environmental factors is of particular importance, since some of these responses are adaptations that allow these fungi to colonize plants leading to AF contamination of crops. Part of these response mechanisms to environmental cues involves the participation of proteins and formation of protein interactions that are unique to fungi, for example VeA and 
VeA-interacting proteins, initially characterized in A. nidulans. For these reasons these protein complexes constitute potential targets for control strategies to reduce the production of $\mathrm{AF}$ and possibly mycotoxin production in other fungi.

Although there are some disparities in the regulation of ST and AF, most of the control mechanisms governing the synthesis of these mycotoxins are conserved. A. nidulans is an excellent model organism to elucidate the complexity of these regulatory networks and provide insight in remediating the impact of $\mathrm{AF}$ contamination.

\section{References}

Adrio, J. L., and A. L. Demain. 2003. Fungal biotechnology. International Microbiology 6 (3):191-199.

Amaike, S., and N. P. Keller. 2009. Distinct Roles for VeA and LaeA in Development and Pathogenesis of Aspergillus flavus. Eukaryotic Cell 8 (7):1051-1060.

Andrianopoulos, A., S. Kourambas, J. A. Sharp, M. A. Davis, and M. J. Hynes. 1998. Characterization of the Aspergillus nidulans nmrA gene involved in nitrogen metabolite repression. Journal of Bacteriology 180 (7):1973-1977.

Araujo-Bazan, L., S. Dhingra, J. Chu, J. Fernandez-Martinez, A. M. Calvo, and E. A. Espeso. 2009. Importin alpha is an essential nuclear import carrier adaptor required for proper sexual and asexual development and secondary metabolism in Aspergillus nidulans. Fungal Genetics and Biology 46 (6-7):506-515.

Arst, H. N., and D. J. Cove. 1973. Nitrogen metabolite repression in Aspergillus-nidulans. Molecular \& General Genetics 126 (2):111-141.

Atoui, A., D. P. Bao, N. Kaur, W. S. Grayburn, and A. M. Calvo. 2008. Aspergillus nidulans natural product biosynthesis is regulated by $\mathrm{mpkB}$, a putative pheromone response mitogen-activated protein kinase. Applied and Environmental Microbiology 74 (11):3596-3600.

Atoui, A., C. Kastner, C. M. Larey, R. Thokala, O. Etxebeste, E. A. Espeso, R. Fischer, and A. M. Calvo. Cross-talk between light and glucose regulation controls toxin production and morphogenesis in Aspergillus nidulans. Fungal Genetics and Biology 47 (12):962-972.

Baidya, S., J. W. Cary, W. S. Grayburn, and A. M. Calvo. 2011. Role of nitric oxide and flavohemoglobin homologous genes in Aspergillus nidulans sexual development and mycotoxin production. Applied Environmental Microbiology, June 3 [Epub ahead of print]

Banuett, F. 1998. Signalling in the yeasts: An informational cascade with links to the filamentous fungi. Microbiology and Molecular Biology Reviews 62 (2):249-+.

Bardwell, L. 2006. Mechanisms of MAPK signalling specificity. Biochemical Society Transactions 34:837-841.

Bayram, O., S. Krappmann, M. Ni, J. W. Bok, K. Helmstaedt, O. Valerius, S. BrausStromeyer, N. J. Kwon, N. P. Keller, J. H. Yu, and G. H. Braus. 2008. VelB/VeA/LaeA complex coordinates light signal with fungal development and secondary metabolism. Science 320 (5882):1504-1506.

Bayram, O., S. Krappmann, S. Seiler, N. Vogt, and G. H. Braus. 2008. Neurospora crassa ve-1 affects asexual conidiation. Fungal Genetics and Biology 45 (2):127-138. 
Bayram, O. S., O. Bayram, O. Valerius, H. S. Park, S. Irniger, J. Gerke, M. Ni, K. H. Han, J. H. $\mathrm{Yu}$, and G. H. Braus. LaeA Control of Velvet Family Regulatory Proteins for LightDependent Development and Fungal Cell-Type Specificity. Plos Genetics 6 (12).

Bennett, J. W., J. J. Dunn, and C. I. Goldsman. 1981. Influence of white-light on production of aflatoxins and anthraquinones in Aspergillus-parasiticus. Applied and Environmental Microbiology 41 (2):488-491.

Bennett, J. W., and M. Klich. 2003. Mycotoxins. Clinical Microbiology Reviews 16 (3):497-+.

Bhatnagar, D., K. C. Ehrlich, and T. E. Cleveland. 2003. Molecular genetic analysis and regulation of aflatoxin biosynthesis. Applied Microbiology and Biotechnology 61 (2):8393.

Bhatnagar, D., and S. P. McCormick. 1988. The inhibitory effect of neem (azadirachta-indica) leaf extracts on aflatoxin synthesis in Aspergillus-parasiticus. Journal of the American Oil Chemists Society 65 (7):1166-1168.

Bok, J. W., and N. P. Keller. 2004. LaeA, a regulator of secondary metabolism in Aspergillus spp. Eukaryotic Cell 3 (2):527-535.

Bradshaw, R. E., and S. G. Zhang. 2006. Biosynthesis of dothistromin. Mycopathologia 162 (3):201-213.

Brakhage, A. A., and V. Schroeckh. Fungal secondary metabolites - Strategies to activate silent gene clusters. Fungal Genetics and Biology 48 (1):15-22.

Brown, D. W., J. H. Yu, H. S. Kelkar, M. Fernandes, T. C. Nesbitt, N. P. Keller, T. H. Adams, and T. J. Leonard. 1996. Twenty-five coregulated transcripts define a sterigmatocystin gene cluster in Aspergillus nidulans. Proceedings of the National Academy of Sciences of the United States of America 93 (4):1418-1422.

Brown, M. P., C. S. Brown-Jenco, and G. A. Payne. 1999. Genetic and molecular analysis of aflatoxin biosynthesis. Fungal Genetics and Biology 26 (2):81-98.

Buchanan, R. L., and D. F. Lewis. 1984. Regulation of aflatoxin biosynthesis - effect of glucose on activities of various glycolytic-enzymes. Applied and Environmental Microbiology 48 (2):306-310.

Burow, G. B., T. C. Nesbitt, J. Dunlap, and N. P. Keller. 1997. Seed lipoxygenase products modulate Aspergillus mycotoxin biosynthesis. Molecular Plant-Microbe Interactions 10 (3):380-387.

Calvo, A. M. 2008. The VeA regulatory system and its role in morphological and chemical development in fungi. Fungal Genetics and Biology 45 (7):1053-1061.

Calvo, A. M., J. Bok, W. Brooks, and N. P. Keller. 2004. veA is required for toxin and sclerotial production in Aspergillus parasiticus. Applied and Environmental Microbiology 70 (8):4733-4739.

Calvo, A. M., H. W. Gardner, and N. P. Keller. 2001. Genetic connection between fatty acid metabolism and sporulation in Aspergillus nidulans. Journal of Biological Chemistry 276 (28):25766-25774.

Calvo, A. M., L. L. Hinze, H. W. Gardner, and N. P. Keller. 1999. Sporogenic effect of polyunsaturated fatty acids on development of Aspergillus spp. Applied and Environmental Microbiology 65 (8):3668-3673.

Calvo, A. M., R. A. Wilson, J. W. Bok, and N. P. Keller. 2002. Relationship between secondary metabolism and fungal development. Microbiology and Molecular Biology Reviews 66 (3):447-+. 
Carbone, I., J. H. Ramirez-Prado, J. L. Jakobek, and B. W. Horn. 2007. Gene duplication, modularity and adaptation in the evolution of the aflatoxin gene cluster. Bmc Evolutionary Biology 7.

Cary, J. W., and K. C. Ehrlich. 2006. Aflatoxigenicity in Aspergillus: molecular genetics, phylogenetic relationships and evolutionary implications. Mycopathologia 162 (3):167-177.

Cary, J. W., B. G. Montalbano, and K. C. Ehrlich. 2000. Promoter elements involved in the expression of the Aspergillus parasiticus aflatoxin biosynthesis pathway gene avnA. Biochimica Et Biophysica Acta-Gene Structure and Expression 1491 (1-3):7-12.

Cary, J. W., G. R. Obrian, D. M. Nielsen, W. Nierman, P. Harris-Coward, J. Y. D. Bhatnagar, T. E. Cleveland, G. A. Payne, and A. M. Calvo. 2007. Elucidation of veA-dependent genes associated with aflatoxin and sclerotial production in Aspergillus flavus by functional genomics. Applied Microbiology and Biotechnology 76 (5):1107-1118.

Cary, J. W., L. Szerszen, and A. M. Calvo. 2009. Regulation of Aspergillus flavus Aflatoxin Biosynthesis and Development. In Mycotoxin Prevention and Control in Agriculture.

Champe, S. P., P. Rao, and A. Chang. 1987. An endogenous inducer of sexual development in Aspergillus-nidulans. Journal of General Microbiology 133:1383-1387.

Chanda, A., L. V. Roze, S. Kang, K. A. Artymovich, G. R. Hicks, N. V. Raikhel, A. M. Calvo, and J. E. Linz. 2009. A key role for vesicles in fungal secondary metabolism. Proceedings of the National Academy of Sciences of the United States of America 106 (46):19533-19538.

Chang, P. K. 2003. The Aspergillus parasiticus protein AFLJ interacts with the aflatoxin pathway-specific regulator AFLR. Molecular Genetics and Genomics 268 (6):711-719.

Chang, P. K. 2004. Lack of interaction between AFLR and AFLJ contributes to nonaflatoxigenicity of Aspergillus sojae. Journal of Biotechnology 107 (3):245-253.

Chang, P. K., J. W. Bennett, and P. J. Cotty. 2002. Association of aflatoxin biosynthesis and sclerotial development in Aspergillus parasiticus. Mycopathologia 153 (1):41-48.

Chang, P. K., J. W. Cary, D. Bhatnagar, T. E. Cleveland, J. W. Bennett, J. E. Linz, C. P. Woloshuk, and G. A. Payne. 1993. Cloning of the Aspergillus-parasiticus apa-2 gene associated with the regulation of aflatoxin biosynthesis. Applied and Environmental Microbiology 59 (10):3273-3279.

Chang, P. K., K. C. Ehrlich, J. J. Yu, D. Bhatnagar, and T. E. Cleveland. 1995. Increased expression of Aspergillus-parasiticus aflR, encoding a sequence-specific dnabinding protein, relieves nitrate inhibition of aflatoxin biosynthesis. Applied and Environmental Microbiology 61 (6):2372-2377.

Chang, P. K., K. Matsushima, T. Takahashi, J. J. Yu, K. Abe, D. Bhatnagar, G. F. Yuan, Y. Koyama, and T. E. Cleveland. 2007. Understanding nonaflatoxigenicity of Aspergillus sojae: a windfall of aflatoxin biosynthesis research. Applied Microbiology and Biotechnology 76:977-984.

Chang, P. K., J. J. Yu, D. Bhatnagar, and T. E. Cleveland. 2000. Characterization of the Aspergillus parasiticus major nitrogen regulatory gene, areA. Biochimica Et Biophysica Acta-Gene Structure and Expression 1491 (1-3):263-266.

Chen, C. B., A. Harel, R. Gorovoits, O. Yarden, and M. B. Dickman. 2004. MAPK regulation of sclerotial development in Sclerotinia sclerotiorum is linked with $\mathrm{pH}$ and cAMP sensing. Molecular Plant-Microbe Interactions 17 (4):404-413. 
Chiang, Y. M., B. R. Oakley, N. P. Keller, and C. C. C. Wang. Unraveling polyketide synthesis in members of the genus Aspergillus. Applied Microbiology and Biotechnology 86 (6):1719-1736.

Cousin, A., R. Mehrabi, M. Guilleroux, M. Dufresne, T. Van der Lee, C. Waalwijk, T. Langin, and G. H. J. Kema. 2006. The MAP kinase-encoding gene MgFus3 of the nonappressorium phytopathogen Mycosphaerella graminicola is required for penetration and in vitro pycnidia formation. Molecular Plant Pathology 7 (4):269-278.

Daniel, P. B., W. H. Walker, and J. F. Habener. 1998. Cyclic AMP signaling and gene regulation. Annual Review of Nutrition 18:353-383.

David, H., I. S. Ozcelik, G. Hofmann, and J. Nielsen. 2008. Analysis of Aspergillus nidulans metabolism at the genome-scale. Bmc Genomics 9.

Davis, N. D., U. L. Diener, and Agnihotr.Vp. 1967. Production of aflatoxins b1 and g1 in chemically defined medium. Mycopathologia Et Mycologia Applicata 31 (3-4):251-\&.

Delgado-Virgen, F., and D. Guzman-de-Pena. 2009. Mechanism of Sterigmatocystin Biosynthesis Regulation by $\mathrm{pH}$ in Aspergillus Nidulans. Brazilian Journal of Microbiology 40 (4):933-942.

Di Pietro, A., F. I. Garcia-Maceira, E. Meglecz, and M. I. G. Roncero. 2001. A MAP kinase of the vascular wilt fungus Fusarium oxysporum is essential for root penetration and pathogenesis. Molecular Microbiology 39 (5):1140-1152.

Doi, K., A. Gartner, G. Ammerer, B. Errede, H. Shinkawa, K. Sugimoto, and K. Matsumoto. 1994. Msg5, a novel protein phosphatase promotes adaptation to pheromone response in Saccharomyces-cerevisiae. Embo Journal 13 (1):61-70.

Dreyer, J., H. Eichhorn, E. Friedlin, H. Kurnsteiner, and U. Kuck. 2007. A homologue of the Aspergillus velvet gene regulates both cephalosporin $C$ biosynthesis and hyphal fragmentation in Acremonium chrysogenum. Applied and Environmental Microbiology 73 (10):3412-3422.

Duran, R., J. W. Cary, and A. M. Calvo. 2009. The role of veA on Aspergillus flavus infection of peanuts, corn and cotton. Open Mycology Journal 3:27-36.

Duran, R. M., J. W. Cary, and A. M. Calvo. 2007. Production of cyclopiazonic acid, aflatrem, and aflatoxin by Aspergillus flavus is regulated by veA, a gene necessary for sclerotial formation. Applied Microbiology and Biotechnology 73:1158-1168.

Dvorackova, I., and V. Kusak. 1990. Hepatocellular carcinoma a 28-year necropsy review. Journal of Environmental Pathology Toxicology and Oncology 10 (4-5):220-224.

Ehrlich, K. C., J. W. Cary, and B. G. Montalbano. 1999. Characterization of the promoter for the gene encoding the aflatoxin biosynthetic pathway regulatory protein AFLR. Biochimica Et Biophysica Acta-Gene Structure and Expression 1444 (3):412-417.

Ehrlich, K. C., and P. J. Cotty. 2002. Variability in nitrogen regulation of aflatoxin production by Aspergillus flavus strains. Applied Microbiology and Biotechnology 60 (1-2):174-178.

Ehrlich, K. C., J. Yu, and P. J. Cotty. 2005. Aflatoxin biosynthesis gene clusters and flanking regions. Journal of Applied Microbiology 99 (3):518-527.

Espeso, E. A., J. Tilburn, H. N. Arst, and M. A. Penalva. 1993. pH regulation is a major determinant in expression of a fungal penicillin biosynthetic gene. Embo Journal 12 (10):3947-3956.

Feng, G. H., and T. J. Leonard. 1998. Culture conditions control expression of the genes for aflatoxin and sterigmatocystin biosynthesis in Aspergillus parasiticus and Anidulans. Applied and Environmental Microbiology 64 (6):2275-2277. 
Fernandes, M., N. P. Keller, and T. H. Adams. 1998. Sequence-specific binding by Aspergillus nidulans AflR, a C-6 zinc cluster protein regulating mycotoxin biosynthesis. Molecular Microbiology 28 (6):1355-1365.

Flaherty, J. E., and G. A. Payne. 1997. Overexpression of aflR leads to upregulation of pathway gene transcription and increased aflatoxin production in Aspergillus flavus. Applied and Environmental Microbiology 63 (10):3995-4000.

Galagan, J. E., S. E. Calvo, C. Cuomo, L. J. Ma, J. R. Wortman, S. Batzoglou, S. I. Lee, M. Basturkmen, C. C. Spevak, J. Clutterbuck, V. Kapitonov, J. Jurka, C. Scazzocchio, M. Farman, J. Butler, S. Purcell, S. Harris, G. H. Braus, O. Draht, S. Busch, C. D'Enfert, C. Bouchier, G. H. Goldman, D. Bell-Pedersen, S. Griffiths-Jones, J. H. Doonan, J. Yu, K. Vienken, A. Pain, M. Freitag, E. U. Selker, D. B. Archer, M. A. Penalva, B. R. Oakley, M. Momany, T. Tanaka, T. Kumagai, K. Asai, M. Machida, W. C. Nierman, D. W. Denning, M. Caddick, M. Hynes, M. Paoletti, R. Fischer, B. Miller, P. Dyer, M. S. Sachs, S. A. Osmani, and B. W. Birren. 2005. Sequencing of Aspergillus nidulans and comparative analysis with A. fumigatus and A. oryzae. Nature 438 (7071):1105-1115.

Georgianna, D. R., A. M. Hawkridge, D. C. Muddiman, and G. A. Payne. 2008. Temperature-dependent regulation of proteins in Aspergillus flavus: Whole organism stable isotope labeling by amino acids. Journal of Proteome Research 7 (7):2973-2979.

Georgianna, D. R., and G. A. Payne. 2009. Genetic regulation of aflatoxin biosynthesis: From gene to genome. Fungal Genetics and Biology 46 (2):113-125.

Gidijala, L., Jakw Kiel, R. A. L. Bovenberg, I. J. Van Der Klei, and M. A. Van Den Berg. Biosynthesis of active pharmaceuticals: beta-lactam biosynthesis in filamentous fungi. In Biotechnology and Genetic Engineering Reviews, Vol 27. Loughborough: Nottingham University Press.

Goodrich-Tanrikulu, M., K. Howe, A. Stafford, and M. A. Nelson. 1998. Changes in fatty acid composition of Neurospora crassa accompany sexual development and ascospore germination. Microbiology-Sgm 144:1713-1720.

Han, K. H., J. A. Seo, and J. H. Yu. 2004. A putative G protein-coupled receptor negatively controls sexual development in Aspergillus nidulans. Molecular Microbiology 51 (5):1333-1345.

Hausladen, A., A. J. Gow, and J. S. Stamler. 1998. Nitrosative stress: Metabolic pathway involving the flavohemoglobin. Proceedings of the National Academy of Sciences of the United States of America 95 (24):14100-14105.

Hicks, Julie K., Kiminori Shimizu, and Nancy P. Keller. 2002. Genetics and biosynthesis of aflatoxins and sterigmatocystin. The Mycota: A comprehensive treatise on fungi as experimental systems for basic and applied research. Agricultural applications:55-69.

Hicks, J. K., J. H. Yu, N. P. Keller, and T. H. Adams. 1997. Aspergillus sporulation and mycotoxin production both require inactivation of the FadA $G$ alpha proteindependent signaling pathway. Embo Journal 16 (16):4916-4923.

Holmes, R. A., R. S. Boston, and G. A. Payne. 2008. Diverse inhibitors of aflatoxin biosynthesis. Applied Microbiology and Biotechnology 78 (4):559-572.

Hsieh, D. P. H., and Mateles. 1970. Relative contribution of acetate and glucose to aflatoxin biosynthesis. Biochimica Et Biophysica Acta 208 (3):482-\&. 
Huffman, J., R. Gerber, and L. C. Du. Recent Advancements in the Biosynthetic Mechanisms for Polyketide-Derived Mycotoxins. Biopolymers 93 (9):764-776.

Hynes, M. J. 1975. Studies on role of area gene in regulation of nitrogen catabolism in Aspergillus-nidulans. Australian Journal of Biological Sciences 28 (3):301-313.

Ignarro, L. J., G. M. Buga, K. S. Wood, R. E. Byrns, and G. Chaudhuri. 1987. Endotheliumderived relaxing factor produced and released from artery and vein is nitric-oxide. Proceedings of the National Academy of Sciences of the United States of America 84 (24):9265-9269.

Jenczmionka, N. J., F. J. Maier, A. P. Losch, and W. Schafer. 2003. Mating, conidiation and pathogenicity of Fusarium graminearum, the main causal agent of the head-blight disease of wheat, are regulated by the MAP kinase gpmk1. Current Genetics 43 (2):87-95.

Joffe, A. Z., and N. Lisker. 1969. Effects of light, temperature, and ph value on aflatoxin production in vitro. Applied Microbiology 18 (3):517-\&.

Kachholz, T., and A. L. Demain. 1983. Nitrate repression of averufin and aflatoxin biosynthesis. Journal of Natural Products 46 (4):499-506.

Kale, S. P., L. Milde, M. K. Trapp, J. C. Frisvad, N. P. Keller, and J. W. Bok. 2008. Requirement of LaeA for secondary metabolism and sclerotial production in Aspergillus flavus. Fungal Genetics and Biology 45 (10):1422-1429.

Kato, N., W. Brooks, and A. M. Calvo. 2003. The expression of sterigmatocystin and penicillin genes in Aspergillus nidulans is controlled by veA, a gene required for sexual development. Eukaryotic Cell 2 (6):1178-1186.

Keller, N. P., C. Nesbitt, B. Sarr, T. D. Phillips, and G. B. Burow. 1997. pH regulation of sterigmatocystin and aflatoxin biosynthesis in Aspergillus spp. Phytopathology 87 (6):643-648.

Keller, N. P., G. Turner, and J. W. Bennett. 2005. Fungal secondary metabolism - From biochemistry to genomics. Nature Reviews Microbiology 3 (12):937-947.

Kim, H. C., J. S. Byun, T. K. Lee, C. W. Jeong, M. Ahn, and T. Shin. 2007. Expression of nitric oxide synthase isoforms in the testes of pigs. Anatomia Histologia Embryologia-Journal of Veterinary Medicine Series C 36 (2):135-138.

Kim, H. S., K. Y. Han, K. J. Kim, D. M. Han, K. Y. Jahng, and K. S. Chae. 2002. The veA gene activates sexual development in Aspergillus nidulans. Fungal Genetics and Biology 37 (1):72-80.

Lafon, A., K. H. Han, J. A. Seo, J. H. Yu, and C. d'Enfert. 2006. G-protein and cAMPmediated signaling in aspergilli: A genomic perspective. Fungal Genetics and Biology 43 (7):490-502.

Lamattina, L., C. Garcia-Mata, M. Graziano, and G. Pagnussat. 2003. Nitric oxide: The versatility of an extensive signal molecule. Annual Review of Plant Biology 54:109136.

Lamb, H. K., J. S. Ren, A. Park, C. Johnson, K. Leslie, S. Cocklin, P. Thompson, C. Mee, A. Cooper, D. K. Stammers, and A. R. Hawkins. 2004. Modulation of the ligand binding properties of the transcription repressor NmrA by GATA-containing DNA and site-directed mutagenesis. Protein Science 13 (12):3127-3138.

Lee, B. N., and T. H. Adams. 1994. Overexpression of flbA, an early regulator of aspergillus asexual sporulation, leads to activation of brlA and premature initiation of development. Molecular Microbiology 14 (2):323-334. 
Lee, B. N., and T. H. Adams. 1996. fluG and flbA function interdependently to initiate conidiophore development in Aspergillus nidulans through brlA beta activation. Embo Journal 15 (2):299-309.

Li, D., P. Bobrowicz, H. H. Wilkinson, and D. J. Ebbole. 2005. A mitogen-activated protein kinase pathway essential for mating and contributing to vegetative growth in Neurospora crassa. Genetics 170 (3):1091-1104.

Li, S. J., K. Myung, D. Guse, B. Donkin, R. H. Proctor, W. S. Grayburn, and A. M. Calvo. 2006. FvVE1 regulates filamentous growth, the ratio of microconidia to macroconidia and cell wall formation in Fusarium verticillioides. Molecular Microbiology 62 (5):1418-1432.

Liu, B. H., and F. S. Chu. 1998. Regulation of aflR and its product, AflR, associated with aflatoxin biosynthesis. Applied and Environmental Microbiology 64 (10):3718-3723.

Marzluf, G. A. 1997. Genetic regulation of nitrogen metabolism in the fungi. Microbiology and Molecular Biology Reviews 61 (1):17-\&.

Masuda, M., T. Kubota, and T. Aso. 2001. Effects of nitric oxide on steroidogenesis in porcine granulosa cells during different stages of follicular development. European Journal of Endocrinology 144 (3):303-308.

Mey, G., K. Held, J. Scheffer, K. B. Tenberge, and P. Tudzynski. 2002. CPMK2, an SLT2homologous mitogen-activated protein (MAP) kinase, is essential for pathogenesis of Claviceps purpurea on rye: evidence for a second conserved pathogenesisrelated MAP kinase cascade in phytopathogenic fungi. Molecular Microbiology 46 (2):305-318.

Meyers, D. M., G. Obrian, W. L. Du, D. Bhatnagar, and G. A. Payne. 1998. Characterization of aflJ, a gene required for conversion of pathway intermediates to aflatoxin. Applied and Environmental Microbiology 64 (10):3713-3717.

Minto, R. E., and C. A. Townsend. 1997. Enzymology and molecular biology of aflatoxin biosynthesis. Chemical Reviews 97 (7):2537-2555.

Monahan, B. J., M. C. Askin, M. J. Hynes, and M. A. Davis. 2006. Differential expression of Aspergillus nidulans ammonium permease genes is regulated by GATA transcription factor AreA. Eukaryotic Cell 5 (2):226-237.

Moriwaki, A., J. Kihara, C. Mori, and S. Arase. 2007. A MAP kinase gene, BMK1, is required for conidiation and pathogenicity in the rice leaf spot pathogen Bipolaris oryzae. Microbiological Research 162 (2):108-114.

Morozov, I. Y., M. Galbis-Martinez, M. G. Jones, and M. X. Caddick. 2001. Characterization of nitrogen metabolite signalling in Aspergillus via the regulated degradation of areA mRNA. Molecular Microbiology 42 (1):269-277.

Morozov, I. Y., M. G. Martinez, M. G. Jones, and M. X. Caddick. 2000. A defined sequence within the 3 ' UTR of the areA transcript is sufficient to mediate nitrogen metabolite signalling via accelerated deadenylation. Molecular Microbiology 37 (5):1248-1257.

Myung, K., S. J. Li, R. A. E. Butchko, M. Busman, R. H. Proctor, H. K. Abbas, and A. M. Calvo. 2009. FvVE1 Regulates Biosynthesis of the Mycotoxins Fumonisins and Fusarins in Fusarium verticillioides. Journal of Agricultural and Food Chemistry 57 (11):5089-5094.

Myung, K., N. C. Zitomer, M. Duvall, A. E. Glenn, R. T. Riley and A. M. Calvo. The conserved global regulator $\mathrm{VeA}$ is necessary for symptom production and 
mycotoxin synthesis in maize seedlings by Fusarium verticillioides. Plant Pathology. article published online: 21 JUL 2011. DOI: 10.1111/j.1365-3059.2011.02504.x"

Ni, M., and J. H. Yu. 2007. A Novel Regulator Couples Sporogenesis and Trehalose Biogenesis in Aspergillus nidulans. Plos One 2 (10).

Nielsen, K. F., J. M. Mogensen, M. Johansen, T. O. Larsen, and J. C. Frisvad. 2009. Review of secondary metabolites and mycotoxins from the Aspergillus niger group. Analytical and Bioanalytical Chemistry 395 (5):1225-1242.

Nierman, W. C., A. Pain, M. J. Anderson, J. R. Wortman, H. S. Kim, J. Arroyo, M. Berriman, K. Abe, D. B. Archer, C. Bermejo, J. Bennett, P. Bowyer, D. Chen, M. Collins, R. Coulsen, R. Davies, P. S. Dyer, M. Farman, N. Fedorova, N. Fedorova, T. V. Feldblyum, R. Fischer, N. Fosker, A. Fraser, J. L. Garcia, M. J. Garcia, A. Goble, G. H. Goldman, K. Gomi, S. Griffith-Jones, R. Gwilliam, B. Haas, H. Haas, D. Harris, H. Horiuchi, J. Huang, S. Humphray, J. Jimenez, N. Keller, H. Khouri, K. Kitamoto, T. Kobayashi, S. Konzack, R. Kulkarni, T. Kumagai, A. Lafton, J. P. Latge, W. X. Li, A. Lord, W. H. Majoros, G. S. May, B. L. Miller, Y. Mohamoud, M. Molina, M. Monod, I. Mouyna, S. Mulligan, L. Murphy, S. O'Neil, I. Paulsen, M. A. Penalva, M. Pertea, C. Price, B. L. Pritchard, M. A. Quail, E. Rabbinowitsch, N. Rawlins, M. A. Rajandream, U. Reichard, H. Renauld, G. D. Robson, S. R. de Cordoba, J. M. Rodriguez-Pena, C. M. Ronning, S. Rutter, S. L. Salzberg, M. Sanchez, J. C. SanchezFerrero, D. Saunders, K. Seeger, R. Squares, S. Squares, M. Takeuchi, F. Tekaia, G. Turner, C. R. V. de Aldana, J. Weidman, O. White, J. Woodward, J. H. Yu, C. Fraser, J. E. Galagan, K. Asai, M. Machida, N. Hall, B. Barrell, and D. W. Denning. 2005. Genomic sequence of the pathogenic and allergenic filamentous fungus Aspergillus fumigatus. Nature 438 (7071):1151-1156.

Norton, R. A. 1999. Inhibition of aflatoxin B-1 biosynthesis in Aspergillus flavus by anthocyanidins and related flavonoids. Journal of Agricultural and Food Chemistry 47 (3):1230-1235.

Obrian, G. R., D. R. Georgianna, J. R. Wilkinson, J. Yu, H. K. Abbas, D. Bhatnagar, T. E. Cleveland, W. Nierman, and G. A. Payne. 2007. The effect of elevated temperature on gene transcription and aflatoxin biosynthesis. Mycologia 99 (2):232-239.

Palmer, R. M. J., D. S. Ashton, and S. Moncada. 1988. Vascular endothelial-cells synthesize nitric-oxide from l-arginine. Nature 333 (6174):664-666.

Palmer, R. M. J., A. G. Ferrige, and S. Moncada. 1987. Nitric-oxide release accounts for the biological-activity of endothelium-derived relaxing factor. Nature 327 (6122):524526.

Paoletti, M., F. A. Seymour, M. J. C. Alcocer, N. Kaur, A. M. Caivo, D. B. Archer, and P. S. Dyer. 2007. Mating type and the genetic basis of self-fertility in the model fungus Aspergillus nidulans. Current Biology 17 (16):1384-1389.

Payne, G. A., and M. P. Brown. 1998. Genetics and physiology of aflatoxin biosynthesis. Annual Review of Phytopathology 36:329-362.

Perrin, R. M., N. D. Fedorova, J. W. Bok, R. A. Cramer, J. R. Wortman, H. S. Kim, W. C. Nierman, and N. P. Keller. 2007. Transcriptional regulation of chemical diversity in Aspergillus fumigatus by LaeA. Plos Pathogens 3 (4):508-517.

Pontecorvo, G., J. A. Roper, L. M. Hemmons, K. D. Macdonald, and A. W. J. Bufton. 1953. The genetics of Aspergillus-nidulans. Advances in Genetics Incorporating Molecular Genetic Medicine 5:141-238. 
Price, M. S., J. J. Yu, W. C. Nierman, H. S. Kim, B. Pritchard, C. A. Jacobus, D. Bhatnagar, T. E. Cleveland, and G. A. Payne. 2006. The aflatoxin pathway regulator AfIR induces gene transcription inside and outside of the aflatoxin biosynthetic cluster. Fems Microbiology Letters 255 (2):275-279.

Purschwitz, J., S. Mueller, C. Kastner, M. Schoser, H. Haas, E. A. Espeso, A. Atoui, A. M. Calvo, and R. Fischer. 2008. Functional and physical interaction of blue- and redlight sensors in Aspergillus nidulans. Current Biology 18 (4):255-259.

Rauyaree, P., M. D. Ospina-Giraldo, S. Kang, R. G. Bhat, K. V. Subbarao, S. J. Grant, and K. F. Dobinson. 2005. Mutations in VMK1, a mitogen-activated protein kinase gene, affect microsclerotia formation and pathogenicity in Verticillium dahliae. Current Genetics 48 (2):109-116.

Rehmeyer, C., W. X. Li, M. Kusaba, Y. S. Kim, D. Brown, C. Staben, R. Dean, and M. Farman. 2006. Organization of chromosome ends in the rice blast fungus, Magnaporthe oryzae. Nucleic Acids Research 34 (17):4685-4701.

Reverberi, M., A. Ricelli, S. Zjalic, A. A. Fabbri, and C. Fanelli. Natural functions of mycotoxins and control of their biosynthesis in fungi. Applied Microbiology and Biotechnology 87 (3):899-911.

Richard, J.L., and G.A. Payne. 2003. Mycotoxins: Risks in Plant and Animal Systems. Council for Agricultural Science and Technology.

Romanov, G. A., S. N. Lomin, N. Y. Rakova, A. Heyl, and T. Schmulling. 2008. Does NO play a role in cytokinin signal transduction? Febs Letters 582 (6):874-880.

Rosen, S., J. H. Yu, and T. H. Adams. 1999. The Aspergillus nidulans sfaD gene encodes a G protein beta subunit that is required for normal growth and repression of sporulation. Embo Journal 18 (20):5592-5600.

Rosselli, M., P. J. Keller, and R. K. Dubey. 1998. Role of nitric oxide in the biology, physiology and pathophysiology of reproduction. Human Reproduction Update 4 (1):3-24.

Roze, L. V., A. E. Arthur, S. Y. Hong, A. Chanda, and J. E. Linz. 2007. The initiation and pattern of spread of histone $\mathrm{H} 4$ acetylation parallel the order of transcriptional activation of genes in the aflatoxin cluster. Molecular Microbiology 66 (3):713-726.

Roze, L. V., R. M. Beaudry, A. E. Arthur, A. M. Calvo, and J. E. Linz. 2007. Aspergillus volatiles regulate aflatoxin synthesis and asexual sporulation in Aspergillus parasiticus. Applied and Environmental Microbiology 73 (22):7268-7276.

Roze, L. V., R. M. Beaudry, N. P. Keller, and J. E. Linz. 2004. Regulation of aflatoxin synthesis by FadA/cAMP/protein kinase A signaling in Aspergillus parasiticus. Mycopathologia 158 (2):219-232.

Roze, L. V., A. M. Calvo, A. Gunterus, R. Beaudry, M. Kall, and J. E. Linz. 2004. Ethylene modulates development and toxin biosynthesis in Aspergillus possibly via an ethylene sensor-mediated signaling pathway. Journal of Food Protection 67 (3):438447.

Roze, L. V., M. J. Miller, M. Rarick, N. Mahanti, and J. E. Linz. 2004. A novel cAMP-response element, CRE1, modulates expression of nor-1 in Aspergillus parasiticus. Journal of Biological Chemistry 279 (26):27428-27439.

Ruiz-Roldan, M. C., F. J. Maier, and W. Schafer. 2001. PTK1, a mitogen-activated-protein kinase gene, is required for conidiation, appressorium formation, and 
pathogenicity of Pyrenophora teres on barley. Molecular Plant-Microbe Interactions $14(2): 116-125$.

Scazzocchio, C. 2000. The fungal GATA factors. Current Opinion in Microbiology 3 (2):126-131. Schinko, T., H. Berger, W. Lee, A. Gallmetzer, K. Pirker, R. Pachlinger, I. Buchner, T. Reichenauer, U. Guldener, and J. Strauss. Transcriptome analysis of nitrate assimilation in Aspergillus nidulans reveals connections to nitric oxide metabolism. Molecular Microbiology 78 (3):720-738.

Schmidt-Heydt, M., A. Abdel-Hadi, N. Magan, and R. Geisen. 2009. Complex regulation of the aflatoxin biosynthesis gene cluster of Aspergillus flavus in relation to various combinations of water activity and temperature. International Journal of Food Microbiology 135 (3):231-237.

Seo, J. A., Y. J. Guan, and J. H. Yu. 2003. Suppressor mutations bypass the requirement of fluG for asexual sporulation and sterigmatocystin production in Aspergillus nidulans. Genetics 165 (3):1083-1093.

Seo, J. A., K. H. Han, and J. H. Yu. 2005. Multiple roles of a heterotrimeric G-protein gammasubunit in governing growth and development of Aspergillus nidulans. Genetics $171(1): 81-89$.

Seo, J. A., and J. H. Yu. 2006. The phosducin-like protein PhnA is required for G beta gamma-mediated signaling for vegetative growth, developmental control, and toxin biosynthesis in Aspergillus nidulans. Eukaryotic Cell 5 (2):400-410.

Shahbazian, M. D., and M. Grunstein. 2007. Functions of site-specific histone acerylation and deacetylation. Annual Review of Biochemistry 76:75-100.

Shantha, T., and V. S. Murthy. 1981. Influence of tricarboxylic-acid cycle intermediates and related metabolites on the biosynthesis of aflatoxin by resting cells of Aspergillusflavus. Applied and Environmental Microbiology 42 (5):758-761.

Shimizu, K., J. K. Hicks, T. P. Huang, and N. P. Keller. 2003. Pka, Ras and RGS protein interactions regulate activity of aflR, a $\mathrm{Zn}(\mathrm{II}) 2 \mathrm{Cys} 6$ transcription factor in Aspergillus nidulans. Genetics 165 (3):1095-1104.

Shimizu, K., and N. P. Keller. 2001. Genetic involvement of a cAMP-dependent protein kinase in a $\mathrm{g}$ protein signaling pathway regulating morphological and chemical transitions in Aspergillus nidulans. Genetics 157 (2):591-600.

Shwab, E. K., J. W. Bok, M. Tribus, J. Galehr, S. Graessle, and N. P. Keller. 2007. Histone deacetylase activity regulates chemical diversity in Aspergillus. Eukaryotic Cell 6 (9):1656-1664.

Smith, C. A., D. Robertson, B. Yates, D. M. Nielsen, D. Brown, R. A. Dean, and G. A. Payne. 2008. The effect of temperature on Natural Antisense Transcript (NAT) expression in Aspergillus flavus. Current Genetics 54 (5):241-269.

Spencer, V. A., and J. R. Davie. 1999. Role of covalent modifications of histones in regulating gene expression. Gene 240 (1):1-12.

Squire, R. A. 1981. Ranking animal carcinogens - a proposed regulatory approach. Science 214 (4523):877-880.

Stinnett, S. M., E. A. Espeso, L. Cobeno, L. Araujo-Bazan, and A. M. Calvo. 2007. Aspergillus nidulans VeA subcellular localization is dependent on the importin alpha carrier and on light. Molecular Microbiology 63 (1):242-255.

Sweeney, M. J., and A. D. W. Dobson. 1999. Molecular biology of mycotoxin biosynthesis. Fems Microbiology Letters 175 (2):149-163. 
Takano, Y., T. Kikuchi, Y. Kubo, J. E. Hamer, K. Mise, and I. Furusawa. 2000. The Colletotrichum lagenarium MAP kinase gene CMK1 regulates diverse aspects of fungal pathogenesis. Molecular Plant-Microbe Interactions 13 (4):374-383.

Tilburn, J., S. Sarkar, D. A. Widdick, E. A. Espeso, M. Orejas, J. Mungroo, M. A. Penalva, and H. N. Arst. 1995. The Aspergillus PacC zinc-finger transcription factor mediates regulation of both acid-expressed and alkaline-expressed genes by ambient $\mathrm{pH}$. Embo Journal 14 (4):779-790.

Trail, F., N. Mahanti, and J. Linz. 1995. Molecular-biology of aflatoxin biosynthesis. Microbiology-Uk 141:755-765.

Tribus, M., J. Galehr, P. Trojer, G. Brosch, P. Loidl, F. Marx, H. Haas, and S. Graessle. 2005. HdaA, a major class 2 histone deacetylase of Aspergillus nidulans, affects growth under conditions of oxidative stress. Eukaryotic Cell 4 (10):1736-1745.

Tsitsigiannis, D., T. M. Kowieski, R. Zarnowski, and N. P. Keller. 2004. Endogenous lipogenic regulators of spore balance in Aspergillus nidulans. Eukaryotic Cell 3 (6):1398-1411.

Tsitsigiannis, D. I., and N. P. Keller. 2006. Oxylipins act as determinants of natural product biosynthesis and seed colonization in Aspergillus nidulans. Molecular Microbiology 59 (3):882-892.

Wendehenne, D., A. Pugin, D. F. Klessig, and J. Durner. 2001. Nitric oxide: comparative synthesis and signaling in animal and plant cells. Trends in Plant Science 6 (4):177183.

Wilkinson, J. R., J. Yu, H. K. Abbas, B. E. Scheffler, H. S. Kim, W. C. Nierman, D. Bhatnagar, and T. E. Cleveland. 2007. Aflatoxin formation and gene expression in response to carbon source media shift in Aspergillus parasiticus. Food Additives and Contaminants 24 (10):1051-1060.

Wilson, R. A., and H. N. Arst. 1998. Mutational analysis of AREA, a transcriptional activator mediating nitrogen metabolite repression in Aspergillus nidulans and a member of the "streetwise" GATA family of transcription factors. Microbiology and Molecular Biology Reviews 62 (3):586-+.

Wogan, G. N. 1992. Aflatoxins as risk-factors for hepatocellular-carcinoma in humans. Cancer Research 52 (7):S2114-S2118.

Wright, M. S., D. M. Greene-McDowelle, H. J. Zeringue, D. Bhatnagar, and T. E. Cleveland. 2000. Effects of volatile aldehydes from Aspergillus-resistant varieties of corn on Aspergillus parasiticus growth and aflatoxin biosynthesis. Toxicon 38 (9):1215-1223.

Xu, J. R., and J. E. Hamer. 1996. MAP kinase and cAMP signaling regulate infection structure formation and pathogenic growth in the rice blast fungus Magnaporthe grisea. Genes \& Development 10 (21):2696-2706.

Yu, J. H., R. A. E. Butchko, M. Fernandes, N. P. Keller, T. J. Leonard, and T. H. Adams. 1996. Conservation of structure and function of the aflatoxin regulatory gene aflR from Aspergillus nidulans and A-flavus. Current Genetics 29 (6):549-555.

Yu, J. J., P. K. Chang, K. C. Ehrlich, J. W. Cary, D. Bhatnagar, T. E. Cleveland, G. A. Payne, J. E. Linz, C. P. Woloshuk, and J. W. Bennett. 2004. Clustered pathway genes in aflatoxin biosynthesis. Applied and Environmental Microbiology 70 (3):1253-1262.

Zeringue, H. J., and S. P. McCormick. 1990. Aflatoxin production in cultures of Aspergillusflavus incubated in atmospheres containing selected cotton leaf-derived volatiles. Toxicon 28 (4):445-448. 
Zhan, X. L., R. J. Deschenes, and K. L. Guan. 1997. Differential regulation of FUS3 MAP kinase by tyrosine-specific phosphatases PTP2/PTP3 and dual-specificity phosphatase MSG5 in Saccharomyces cerevisiae. Genes $\mathcal{E}$ Development 11 (13):16901702. 


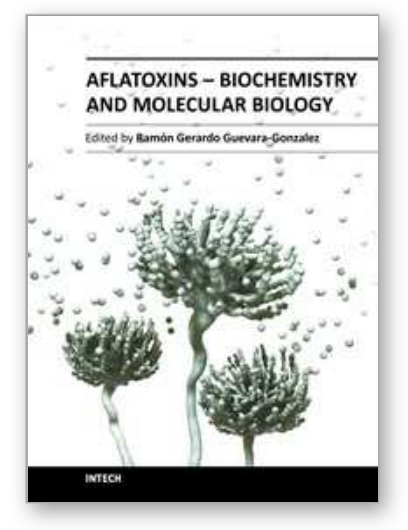

\author{
Aflatoxins - Biochemistry and Molecular Biology \\ Edited by Dr. Ramon G. Guevara-Gonzalez
}

ISBN 978-953-307-395-8

Hard cover, 468 pages

Publisher InTech

Published online 03, October, 2011

Published in print edition October, 2011

Aflatoxins â€" Biochemistry and Molecular Biology is a book that has been thought to present the most significant advances in these disciplines focused on the knowledge of such toxins. All authors, who supported the excellent work showed in every chapter of this book, are placed at the frontier of knowledge on this subject, thus, this book will be obligated reference to issue upon its publication. Finally, this book has been published in an attempt to present a written forum for researchers and teachers interested in the subject, having a current picture in this field of research about these interesting and intriguing toxins.

\title{
How to reference
}

In order to correctly reference this scholarly work, feel free to copy and paste the following:

Ana M. Calvo and Sourabh Dhingra (2011). Conserved Regulatory Mechanisms Controlling Aflatoxin and Sterigmatocystin Biosynthesis, Aflatoxins - Biochemistry and Molecular Biology, Dr. Ramon G. GuevaraGonzalez (Ed.), ISBN: 978-953-307-395-8, InTech, Available from:

http://www.intechopen.com/books/aflatoxins-biochemistry-and-molecular-biology/conserved-regulatorymechanisms-controlling-aflatoxin-and-sterigmatocystin-biosynthesis

\section{INTECH}

open science | open minds

\section{InTech Europe}

University Campus STeP Ri Slavka Krautzeka 83/A 51000 Rijeka, Croatia Phone: +385 (51) 770447

Fax: +385 (51) 686166 www.intechopen.com

\section{InTech China}

Unit 405, Office Block, Hotel Equatorial Shanghai No.65, Yan An Road (West), Shanghai, 200040, China 中国上海市延安西路65号上海国际贵都大饭店办公楼405单元 Phone: +86-21-62489820

Fax: +86-21-62489821 
(C) 2011 The Author(s). Licensee IntechOpen. This is an open access article distributed under the terms of the Creative Commons Attribution 3.0 License, which permits unrestricted use, distribution, and reproduction in any medium, provided the original work is properly cited. 